\section{Commentary: Aortic valve disease: Getting in the way of mechanical circulatory support}

\author{
James A. Brown, MA, ${ }^{\mathrm{a}}$ and Ibrahim Sultan, $\mathrm{MD}^{\mathrm{a}, \mathrm{b}}$
}

Cardiogenic shock from advanced heart failure is associated with a high mortality rate and can be temporized and managed with mechanical circulatory support (MCS). MCS options include destination therapy or bridge-totransplantation strategy with a durable ventricular assist device (VAD) or a bridge-to-decision strategy that seeks to stabilize critically ill patients with life-threatening hypotension before implanting a durable VAD. Historically, temporary MCS options have included venoarterial extracorporeal membrane oxygenation (ECMO) and percutaneous VADs, such as the Impella (Abiomed, Danvers, Mass). In this issue of JTCVS Techniques, Goodwin and colleagues ${ }^{1}$ present an innovative approach in which they employed a transapical approach with a ProtekDuo (TandemLife, Pittsburgh, Pa) cannula for temporary MCS.

In this case report, a 51-year-old man with a history of 2 previous coronary artery bypass graft operations and New York Heart Association class IV heart failure presented with severe cardiogenic shock. In the setting of life-threatening hypotension refractory to inotropic therapy, temporary MCS was initiated to resuscitate this patient as a bridge to durable VAD implantation. Given the patient's previous sternotomies, central ECMO was not an ideal option. Since the patient also

From the a Division of Cardiac Surgery, Department of Cardiothoracic Surgery, University of Pittsburgh; and ${ }^{\mathrm{b}} \mathrm{Heart}$ and Vascular Institute, University of Pittsburgh Medical Center, Pittsburgh, Pa.

Disclosures: I.S. receives institutional research support from Medtronic and AtriCure. These conflicts are not related to this article. J.A.B. reported no conflicts of interest. The Journal policy requires editors and reviewers to disclose conflicts of interest and to decline handling or reviewing manuscripts for which they may have a conflict of interest. The editors and reviewers of this article have no conflicts of interest.

Received for publication Nov 22, 2020; revisions received Nov 22, 2020; accepted for publication Nov 26, 2020; available ahead of print Dec 5, 2020.

Address for reprints: Ibrahim Sultan, MD, Division of Cardiac Surgery, Department of Cardiothoracic Surgery, University of Pittsburgh, Center for Thoracic Aortic Disease, Heart and Vascular Institute, University of Pittsburgh Medical Center, 5200 Centre Ave, Suite 715, Pittsburgh, PA 15232 (E-mail: sultani@upmc.edu). JTCVS Techniques 2021;5:80-1

2666-2507

Copyright (C) 2020 The Authors. Published by Elsevier Inc. on behalf of The American Association for Thoracic Surgery. This is an open access article under the CC BY-NCND license (http://creativecommons.org/licenses/by-nc-nd/4.0/).

https://doi.org/10.1016/j.xjtc.2020.11.031

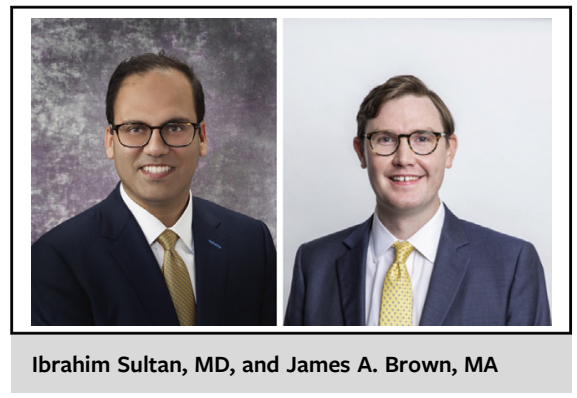

CENTRAL MESSAGE

In the setting of significant aortic valve disease, transapical cannu-

lation for temporary mechanical

circulatory support may be

technically more appropriate

than peripheral approaches.

had moderate-to-severe aortic regurgitation with moderate aortic stenosis, peripheral ECMO and Impella were suboptimal choices. For these reasons, the authors employed a transapical approach to place the ProtekDuo cannula.

The technique described in this case report can be considered a technical success because the left ventricle (LV) was adequately decompressed and the patient was able to subsequently engage in physical therapy. However, a few questions remain. Given the patient's INTERMACS (Interagency Registry for Mechanically Assisted Circulatory Support) profile, the authors opted for a temporary MCS strategy to improve hemodynamics and end-organ perfusion, in view of (hopefully) reducing immediate morbidity and mortality. To be clear, the decision to initiate temporary MCS, as opposed to immediately implanting a durable VAD, is logically independent of the decision whether to use a transapical or an axillary approach for temporary MCS. While logic and clinical judgment support the strategy of temporary MCS as bridge to decision or durable VAD, the long-term data to support this strategy are rather limited. ${ }^{2-5}$ Admittedly, these divergent results may be due to differing times from initiation of temporary MCS to durable VAD implantation in each of the studies. The authors are to be congratulated for a safe technical outcome. However, it is unlikely that a universal transapical approach is likely to be safe in all patients. Older patients with dilated and thin-walled LVs, inability to safely manage 
the LV apex, and complications from a thoracotomy approach can all be challenging scenarios in these critically ill patients. ${ }^{2-4,6}$

Aortic valve disease can significantly complicate the use of MCS for managing patients with advanced heart failure. Aortic valve pathology, particularly aortic regurgitation in the setting of MCS, will cause the LV to distend with retrograde flow. This, in addition to concomitant aortic stenosis, would be the primary reason for attempting a transapical approach as opposed to an axillary Impella. Moreover, as the authors argue, the CentriMag pump connected to the ProtekDuo cannula may provide superior offloading of the $\mathrm{LV}$ as well as minimal anticoagulation requirements and negligible hemolysis, as compared with an axillary Impella approach. Whether temporary MCS before durable VAD is the commendable strategy for patients who are INTERMACS level 1, the authors should be congratulated for their innovative use of the transapical approach for their patient with acute decompensated heart failure and concomitant aortic valve pathology.

\section{References}

1. Goodwin ML, Roberts S, Lampert BC, Whitson BA. Temporary extracorporeal left ventricular support with transapical ProtekDuo cannula. J Thorac Cardiovasc Surg Tech. 2021:5:76-9.

2. Yoshioka D, Takayama H, Garan AR, Topkara VK, Han J, Li B, et al. Bridge to durable left ventricular assist device for refractory cardiogenic shock. $J$ Thorac Cardiovasc Surg. 2017;153:752-62.e5.

3. Ando M, Garan AR, Takayama H, Topkara VK, Han J, Kurlansky P, et al. A continuous-flow external ventricular assist device for cardiogenic shock: evolution over 10 years. J Thorac Cardiovasc Surg. 2018;156:157-65.e1.

4. Shah P, Pagani FD, Desai SS, Rongione AJ, Maltais S, Haglund NA, et al. Outcomes of patients receiving temporary circulatory support before durable ventricular assist device. Ann Thorac Surg. 2017;103:106-12.

5. Vallabhajosyula S, Arora S, Lahewala S, Kumar V, Shantha GPS, Jentzer JC, et al Temporary mechanical circulatory support for refractory cardiogenic shock before left ventricular assist device surgery. J Am Heart Assoc. 2018;7:e010193.

6. Sultan I, Kilic A, Kilic A. Short term circulatory and right ventricle support in cardiogenic shock: ECMO, Tandem Heart, CentriMag and Impella. Heart Fail Clin. 2018;14:579-83. 